MEDICAL EDUCATION

\title{
MMed cohort supervision: A path out of the swamp?
}

\begin{abstract}
C Rout, T Sommerville, C Aldous
Chris Rout, MB BS, FFARCS, FCA (SA), erstwhile Research Professor and currently a sessional specialist in the Department of Anaesthetics, Nelson Mandela School of Medicine, College of Health Sciences, University of KwaZulu-Natal (UKZN), Durban, South Africa, is in private anaesthetic practice in Durban. He maintains a research interest in obstetric anaesthesia and is developing interests in clinical skills transfer, clinical support needs of medical officers in rural district hospitals, and the influence of Plato on 15th century Florentine art. Ted Sommerville, MB ChB, BSc (Med), $D A, F F A, P h D$ (Higher Education), previously Director and Head of Department, School of Undergraduate Medical Education, UKZN, is currently semi-retired, facilitating research, tending bonsai and teaching at the local primary school. Colleen Aldous is a senior lecturer in the School of Clinical Medicine at UKZN. She is a medical scientist with a PhD in science education and is involved in postgraduate research mentorship across several medical disciplines including surgery, orthopaedics, dermatology, paediatrics, opthalmology, general medicine and psychology. Her own research interest is human genetics, and she is a member of the national steering committee and working group reviewing National Department of Health policy guidelines for human genetics services.
\end{abstract}

Corresponding author: C Rout (rout@ukzn.ac.za)

The authors present the case for collaborative cohort supervision (CCM), including both master's students and novice supervisors, as a possible way to rapidly increase the number of supervisors needed to address the recent implementation of a compulsory research component to specialist registration with the Health Professions Council of South Africa. Different models of CCM are discussed and possible pitfalls highlighted.

S Afr Med J 2015;105(4):275-276. DOI:10.7196/SAMJ.9338

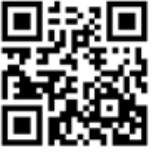

The problems currently facing many clinical departments in providing appropriate supervision for the research component of the MMed degree have been highlighted in the SAMJ..$^{[1,2]}$ The most pressing issues are the inadequate numbers of potential supervisors available and time allocation for research activities. Clearly the traditional apprentice-master model (AMM) of one supervisor to one student will not meet the throughput demands of the Health Professions Council of South Africa, the Colleges of Medicine of South Africa and clinical departments, and the one-supervisor-multiplestudents model has two problems. Firstly the supervisor is not likely to have enough time to take on several students and ensure thorough supervision for all, and secondly many potential clinical supervisors may not yet have developed the skills and experience to supervise students in the research process as well as the clinical discipline.

\section{Joint supervision}

One possible path to be explored is that of joint supervision. There are four options by which joint supervision can be achieved:

1. Two supervisors to one student

2. Two supervisors to a cohort of students within a single discipline

3. Two or more disciplinary and research process supervisors to a cohort of students from different disciplines

4. One or more supervisors to a cohort of students and a cohort of novice supervisors.

Clearly option 1 is numerically inappropriate for a department that is battling to find supervisors, and differs little from the traditional AMM. However, this model may be suitable in a department where a specialist with the requisite qualifications but lacking supervision experience is paired with an experienced supervisor. This is the purpose of the Council for Higher Education recommendation: 'In the case of inexperienced or new supervisors, there is ongoing staff development and support, and joint supervision is explored as an option. ${ }^{[3]}$
However, some centres are using this form of joint supervision to compensate for the absence of a supervisor with '... a qualification in a relevant field of study higher than, or at least at the same level as, the exit level of the postgraduate programme he/she is supervising? ${ }^{[3]}$. While it could be argued that the latter is the least important of the regulations, this practice is effectively ignoring their purpose, but is applied by academic administrators as a way of complying with the regulations without any thought.

Options 2, 3 and 4, all collaborative cohort models (CCMs), provide effective gearing for student research within a limited population of supervisors, but only option 4 addresses the immediate need for more supervisors. Disciplinary supervisors, who may be relatively research-naive, focus on discipline-specific aspects of the research; the research process supervisors, who may be unfamiliar with the disciplinary contexts, enhance the scientific process within the accepted canon and enrich it by introducing possible alternative approaches. In this article we explore the advantages and possible pitfalls of cohort supervision.

\section{Cohort supervision}

CCMs have been evolving in postgraduate supervision for over 50 years as part of the debate surrounding solutions for poor completion rates for postgraduate degrees. ${ }^{[4]}$ Option 2 may be feasible for larger departments, and may be preferable to two (or more) staff members separately being allocated groups of students. Option 3 may make more efficient use of resources from several departments, but risks becoming too elaborate and labour-intensive. Furthermore, if a faculty is simultaneously to develop the supervisory skills of its staff, the obvious solution of pairing experienced and inexperienced supervisors would throw a double mentoring load on the experienced supervisor in options $1-3$.

Option 4 has the advantage of combining the benefits accruing to students participating in multimember groups ${ }^{[5]}$ with modelling the supervisor's role for the benefit of disciplinary specialists 


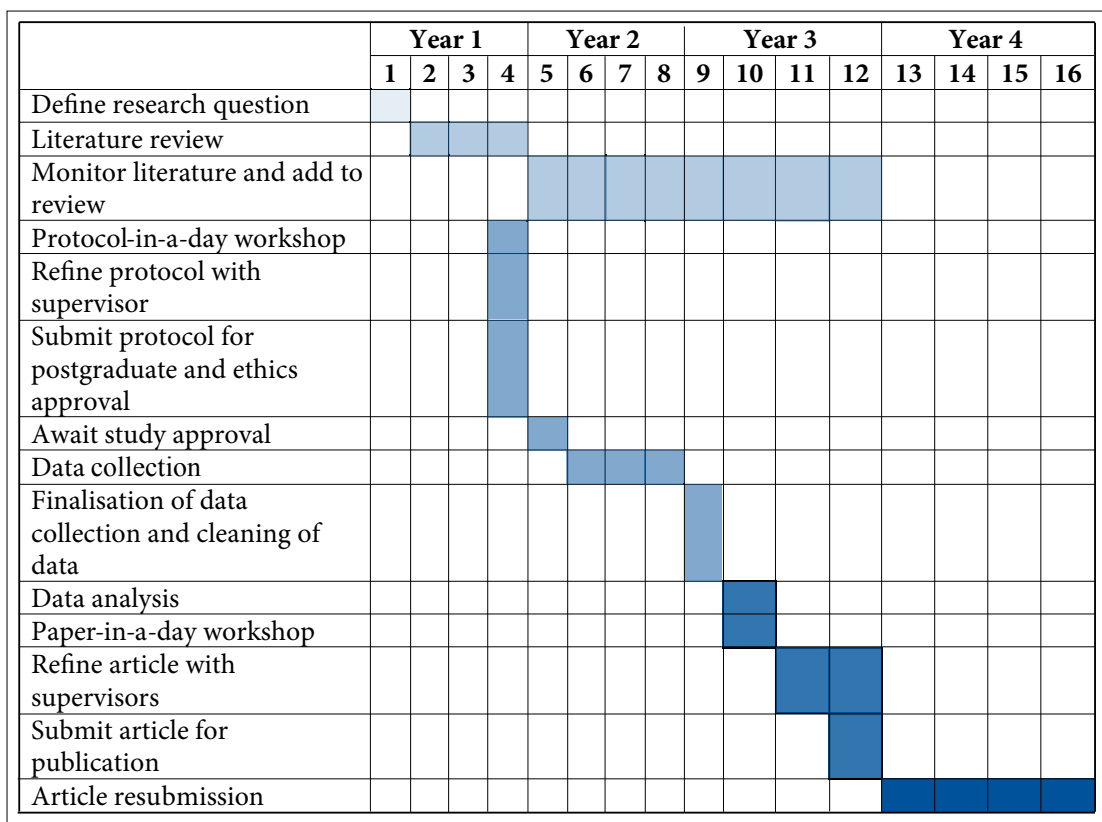

Fig. 1. Gant chart for MMed research project process through 16 year-quarters.

unaccustomed to that role. Postgraduate students need to be inducted into the functional elements of proposal writing, data gathering and reporting, enculturated into a community of scholarly practice, encouraged to think critically about what they are doing and why, emancipated to the point that the student rather than the supervisor owns the research, and given sufficient pastoral care to see them through the inevitable tough times. ${ }^{[6]}$ Similarly, novice supervisors need to see these elements of the research process enacted by those more experienced than themselves.

For the purposes of the MMed, we believe that the CCM model must include both students and supervisors. This avoids the possibility of the CCM group contradicting a student's own supervisor. If the group is large enough, more homogeneous subgroups (based upon either discipline or research design) may separate within the process to discuss matters of specific relevance, thereby also affording more individualised guidance of students. Effectively, students belong to two cohorts: disciplinary and research method.

There is a danger that the process may adopt a linear seminar-based approach, which is not the intention. One way to avoid this is to use a goal-directed model where the objectives of each group meeting are planned in advance, based upon milestones within the research process; Gant charts can be particularly useful in this regard. An example of a chart applied at the Grey's Hospital Department of Surgery is shown in Fig. 1.
A more open 'rolling entry' model, such as that used by Burnett, ${ }^{[4]}$ is better suited to MMedSci and $\mathrm{PhD}$ students, who are more familiar with the research process than MMed students and do not have the same time constraints. Above all, the students must take ownership of the meetings, presenting their projects, defending their work and contributing to the work of others as part of a peer review process. Novice supervisors, if option 4 is applied, acquire skills in mentorship, group supervision, supervisory advice and positive critique. ${ }^{[7]}$ Meetings must not devolve into a session of talking heads and passive audience.

The main drawbacks of any cohort model in the context of clinical medicine are logistical. Firstly, whatever the timetable for the sessions, both trainees and disciplinary specialists would be removed simultaneously from clinical service. The chances are that both students and novice supervisors will be from the same discipline, exacerbating the problem, particularly in small clinical departments. Secondly, different disciplines may focus on the research component of professional training at different times during the 4-year programme, and examination timetables have to be considered. Thirdly, particularly in disciplines with scant undergraduate exposure, trainees may be unfamiliar with possible areas within the specialty in which they might find a research interest. While the latter applies to all supervision models, it presents a particular problem with CCM in terms of when to commence the programme. How these issues are surmounted will vary between institutions, and no general recommendation is possible other than that research time has to be provided for trainees and their supervisors, as has been highlighted previously, ${ }^{[1]}$ whatever the supervision model.

Compulsory research programmes as part of professional registration differ from those discussed in the literature in three ways: the research is generally viewed by postgraduate students/trainees not as inherently desirable but as a necessary evil on the path to specialisation; the clinical service load must continue to be borne by the postgraduate students/trainees; and at present in South Africa many institutions have to grow their own supervisor wood while cultivating the MMed crop. We argue that setting a systematic supervision process in place would mitigate the first two challenges. Finding time for scholarship in the face of a growing clinical load is a matter that must also be addressed.

The introduction of a system that is costly both in time and personnel must be appropriately monitored to ensure that it meets the needs of specialist disciplines, students and supervisors and is timed to the convenience of all groups, not that of university calendars. Any feedback from questionnaire data must be actively processed and used to modify the programme in successive years to ensure mutual benefit. ${ }^{[8]}$ This is particularly important with an externally motivated process such as compulsory research.

The lack of literature specific to supervision of compulsory research means that we are heading into uncharted territory. Any method of potential value must be approached with an open mind and embedded quality assurance programmes.

\footnotetext{
1. Aldous C, Adhikari M, Rout C. The research component of specialist registration - a question of alligators and swamps? specialist registration - a question of alligators and swamps?
A personal view. S Afr Med J 2015;105(1):21-22. [http://dx.doi. A personal view. S Afr M
org/10.7196/SAMJ.8732]

2. Seggie J. On getting published in the SAMJ. S Afr Med J 2. Seggie J. On getting published in the SAMJ. S Afr M
2015;105(2):77-78. [http://dx.doi.org/10.7196/SAMJ.9348]

3. Council for Higher Education criteria for programme accreditation, November 2004. 3.1.8 Postgraduate policies, procedures and regulations: Criterion 9. (ii). http:/nr-online.che. ac.za/html_documents/CHE_accreditation_criteria_Nov2004. pdf (accessed 28 July 2014).

4. Burnett P. The supervision of doctoral dissertations using a collaborative cohort model. Counselor Education and Supervision 1999;39(1):46-52. [http://dx.doi.org/10.1002/j.1556-6978.1999. tb01789.x]

5. Samuel M, Vithal R. Emergent frameworks of research teaching and learning in a cohort-based doctoral programme. Perspectives in Education 2011;29(3):76-87.

6. Lee A. How are doctoral students supervised? Concepts of doctoral research supervision. Studies in Higher Education doctoral research supervision. Studies in Higher Education
2008;33(3):267-281. [http://dx.doi.org/10.1080/030750708020

7. De Lange N, Pillay G, Chikoko V. Doctoral learning: A case for a cohort model of supervision and support. South African Journal of Education 2011;31(1):15-30.

8. Stalmeijer R, Whttingham J, de Grave W, Dolmans D. Strengthening internal quality assurance processes: Facilitating student evaluation committees to contribute. Assessment and Evaluation in Higher Education 2014. [http://dx.doi.org/10.108 0/02602938.2014.976760]
}

Accepted 12 January 2015. 